\title{
Influence of supplementary cementitious materials on hydration and microstructure development of concrete
}

\author{
A.I. Nicoara 1,2, (D), R. Trusca ${ }^{2}$, O. Oprea 1,2, B.S. Vasile 1,2 \\ 1 Faculty of Applied Chemistry and Materials Science, Politehnica University of Bucharest, Bucharest, 060042, Romania \\ 2 National Centre for Micro and Nanomaterials, Politehnica University of Bucharest, Bucharest, 060042, Romania \\ * Correspondence: adi.nicoara18@gmail.com; Scopus ID: 57189267841
}

Several supplementary cementitious materials (SCM) were blended with Portland cement clinker in order to produce more sustainable binders. The use of such materials, where no additional clinkering process is involved, leads to a significant reduction in $\mathrm{CO}_{2}$ emissions per ton of cementitious materials (grinding, mixing and transport of concrete and use very little energy compared to the clinkering process) and is a means to (re)utilize by-products of industrial manufacturing processes. Fly ash, for example, is the most commonly used supplementary cementitious material.

The blending of Portland cement with fly ash results in the reduction of the total amount of portlandite in the hydrated mixture [1-4], somewhat less pronounced than for silica fume as: the reactivity of fly ash is very limited and as the $\mathrm{CaO}$ in the fly ash is an additional source of calcium [5].

Since fly ash particles are more spherical in shape than cement particles, workability and pumpability can be improved, by adding fly ash, also, fly ashes can cause low early strengthening. In this paper, the effects of Fly-ash as SCM's on microstructure and hydration kinetics are studied. Keywords: concrete, fly ash, bydration kinetics.

\section{Funding}

Re-generating (raw) materials and end-of-life products for re-use in Cement/Concrete (RECEMENT)ERAMIN2, ctr. No. 115/01/10/2019.

\section{Acknowledgments}

Not applicable.

\section{Conflicts of Interest}

The authors declare no conflict of interest. 

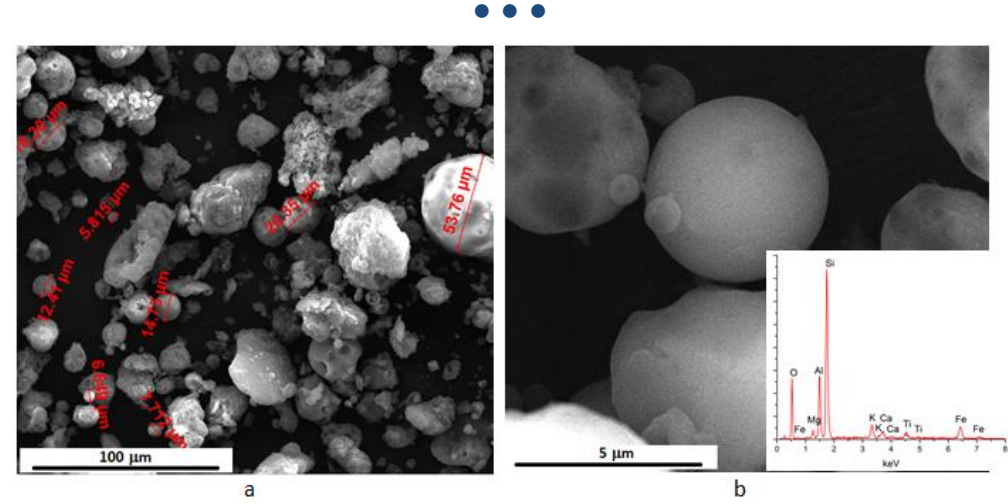

Figure 1. Scanning electron microscopy (SEM) images and EDS spectra on fly-ash (a and b).

\section{References}

1. Hanehara, S.; Tomosawa, F.; Kobayakawa, M.; Hwang, K.R. Effects of water/powder ratio, mixing ratio of fly ash, and curing temperature on pozzolanic reaction of fly ash in cement paste. Cement and Concrete Research 2001, 31, 31-19, https://doi.org/10.1016/S00088846(00)00441-5.

2. Snyder, K.A.; Stutzman, P.E.; Philip, J.; Esh, D. Hydrated phases in blended cementitious systems for nuclear infrastructure, Longterm Performance of Cementitious Barriers and Reinforced Concrete in Nuclear Power Plants and Waste Management. NUCPERF, RILEM, Cadarache, France 2009; pp. 91-98.
3. Lam, L.; Wong, Y. L.; Poon, C.S. Degree of hydration and gel/space ratio of high volume fly ash/cement systems. Cement and Concrete Research 2000, 30, 747-756, http://dx.doi.org/10.1016/S0008-8846(00)00213-1.

4. Papadakis, V.G. Effect of fly ash on Portland cement systems. Part II: high-calcium fly ash. Cement and Concrete Research 2000, 30, 1647-165, https://doi.org/10.1016/S0008-8846(00)00388-4.

5. Hong, S.Y.; Glasser, F.P. Alkali binding in cement pastes. Part I. The $\mathrm{C}-\mathrm{S}-\mathrm{H}$ phase. Cement and Concrete Research 1999, 29, 1893-1903.

(C) 2019 by the authors. This article is an open access article distributed under the terms and conditions of the Creative Commons Attribution (CC BY) license (http://creativecommons.org/licenses/by/4.0/). 